\title{
Catheter Occlusion By Calcium Carbonate: A Well-Known Problem Persists in Spite of Better Knowledge
}

\author{
D. Lüftner D. Jozereau K. Possinger \\ Medizinische Klinik und Poliklinik II, Universitätsklinikum Charité, Campus Mitte, Humboldt-Universität zu Berlin, Germany
}

The so-called 'AIO' regimen with high-dose 5-FU (5-fluorouracil) and calcium folinate is a standard regimen in the treatment of advanced colorectal cancer. In this well-known combination therapy, the 2-h infusion of calcium folinate (500 $\mathrm{mg} / \mathrm{m}^{2}$ ) precedes the $24-\mathrm{h}$ continuous infusion with high-dose 5 -FU $\left(2,600 \mathrm{mg} / \mathrm{m}^{2}\right)$. The basis for this schedule was given by the clinical study done by Ardalan and co-workers in the year 1991 [1]. In the original regimen, 5-FU and calcium folinate were administered simultaneously via a central venous device, generally a Hickman catheter or a port-a-cath ${ }^{\circledR}$ system.

Why are calcium folinate and 5-FU applied sequentially in the AIO-regimen although the original data were produced with a mixed infusion?

To answer this question we have to look back to the early times of treatment of metastatic colorectal cancer with calcium folinate and high-dose 5-FU. First pre-clinical studies had been done on human colon cancer xenografts comparing different infusion schedules of calcium folinate. By comparing i.v. bolus, 4-h infusion and 24-h infusion schedules of fixed doses of calcium folinate and 5-FU, variations of reduced folate levels in human colon cancer xenografts depending on the duration of infusion could be demonstrated [2]. Interestingly, the most pronounced increases of intratumoral folate levels were seen after the 24-h infusion.

Based on these data, Ardalan and co-workers started their clinical study with 5-FU and calcium folinate mixed together in a continuous infusion over $24 \mathrm{~h}$ [1]. By using this new schedule they reached a remarkable response rate accompanied by a survival time of more than 22 months and moderate toxicity. Unfortunately, it became evident that many catheters were obstructed by crystal formation after a certain number of cycles. As a consequence, Ardalan et al. changed the mode of administration and furthermore used two separate venous accesses to avoid catheter occlusion. Four years later, Ardalan reported in full length that 11 of the 22 treated patients had developed a catheter blockade due to formation of calcium carbonate (calcite) [3]. The time from initiation of therapy to catheter obstruction ranged from 8 to 24 weeks.

After the encouraging clinical results of the 'Ardalan' schedule, the original regimen was modified by other groups to avoid the inconvencience of two i.v. infusions which led to the development of the 'AIO' variant, i.e. the prior administration of a 2-h infusion of calcium folinate followed by the 24-h infusion of 5-FU via a portable infusion pump. This mode of application represented a compromise between the need for one i.v. device only and the pharmacological rationale of parallel toxification of 5-FU by folinic acid. However, keeping in mind the half lives of folinic acid with approximately 7 hours and 5FU with a few minutes, this compromise a priori renounces optimal toxification of 5-FU, especially towards the end of the 24-h infusion.

In the first quarter of 2002, the initially restricted approval for calcium folinate was extended and then permitted the mixture of calcium folinate with 5-FU. The basis for this extension was the in vitro compatibility without any loss of drug by complex formation for $48 \mathrm{~h}$ in a mixture of calcium folinate $(4 \mathrm{mg} / \mathrm{ml})$ and 5 -FU $(20 \mathrm{mg} / \mathrm{ml})$ as demonstrated by high performance liquid chromatography (HPLC). These data were integrated into the summary of producer characteristics (SPC) of several suppliers without any further in vivo confirmation at that time. Based on this presumably valid recommendation, Bruch and Esser started biomodulated, high-dose 5-FU therapy in a patient with stage IV rectal cancer and administered a mixture of calcium folinate and 5-FU over a period of $24 \mathrm{~h}$ once a week via a port-a-cath as described in a case report in this volume [4]. During the course of this therapy, the patient developed port occlusion and needed port explantation. The thorough work-up of the occluding firm material from inside the lumen of the removed catheter revealed calcium carbonate as reason for the obstruction. The time to development of

\begin{tabular}{ll}
\hline KARGER & @ 2003 S. Karger GmbH, Freiburg \\
Fax +49 7614520714 & Accessible online at: \\
$\begin{array}{l}\text { E-mail Information@Karger.de } \\
\text { www.karger.com }\end{array}$ & www.karger.com/onk
\end{tabular}

Dr. med. Diana Lüftner

Medizinische Klinik und Poliklinik II, Schwerpunkt Onkologie und Hämatologie

Universitätskinikum Charité, Campus Mitte, Humboldt-Universität zu Berlin

Schumannstr. 20-21, D-10117 Berlin

Tel. +49 30 450-513259, Fax -513972

E-mail Diana.Lueftner@rz.hu-berlin.de or diana.lueftner@charite.de 
catheter blockage after 11 applications is in line with the publications by Ardalan et al. in 1991 and 1995 [1, 3]. Discussions with clinical oncologists indicate that this case report is not an exception.

Does this change of recommendations withstand critical discussion?

The analysis of the mixture of 5-FU and folinic acid which led to the extension of approval was a solely physical and chemical in vitro examination. No loss of any of the two drugs had been observed, which was interpreted as sufficient to assume compatibility not only for one infusional maneuver but over a longer period with several protracted infusions. In this decision process, an increase of the $\mathrm{pH}$ value and a slightly intensified yellow color of the mixture had not been considered as indicators for a reaction between the both components. Thus, an important change of the standard of care of an epidemiologically relevant tumor had taken place without any regard of previously available and well-published information. No clinical data indicated that the mixture of both drugs was safe. This is even more severe as another group had reported of crystal precipitation when calcium folinate and 5-FU were mixed in vitro [5]. It was only in December 2002 that one supplier warned of a mixture of calcium folinate with 5-FU in the same infusional system [6].

How do standard recommendations change so abruptly without underlying evidence?

Interestingly, the promotion of the mixed application of calcium folinate coincided with the availability and increasing acceptance of sodium folinate as competing drug. However, the mixture of the sodium salt of folinic acid and 5-FU had been tested beyond a pure in vitro compatibility and had proven clinical feasibility under routine conditions in portable pump systems [7]. Physicians must be very aware of the bias of data pushed forward by the pharmaceutical industry in times of very hard economic restraints and competition.

In conclusion, we cannot recommend the simultaneous administration of calcium folinate and 5-FU admixed in one pump. There are only two safe methods of administering folinic acid in combination with 5-FU: If oncologists prefer the use of calcium folinate, they should apply calcium folinate and 5FU sequentially as described by the AIO regimen. If oncologists favor the simultaneous application of folinic acid together with 5-FU admixed in one ambulatory pump for pharmacological reasons, they should use the sodium salt of folinic acid.

\section{References}

1 Ardalan B, Chua L, Tian E, Reddy R, Sridhar K, Benedetto P, Richman S, Legaspi A, Waldman S, Morrell L, Feun L, Savaraj N, Livingstone A: A phase II study of weekly 24-hour infusion with high-dose fluorouracil with Leucovorin in colorectal carcinoma. J Clin Oncol 1991;9:625-630.

2 Houghton JA, Williams LG, de Graaf SS, Cheshire PJ, Rodman JH, Maneval DC, Wainer IW, Jadaud P, Houghton PJ: Relationship between dose rate of [6RS]Leucovorin administration, plasma concentrations of reduced folates, and pools of 5,10-methylenetetrahydrofolates and tetrahydrofolates in human colon adenocarcinoma xenografts. Cancer Res 1990;50:3493-3502.
3 Ardalan B, Flores MR: A new complication of chemotherapy administered via permanent indwelling central venous catheter. Cancer 1995;75:2165-2168.

4 Bruch HR, Esser M: Catheter occlusion by calcium carbonate druring simultaneous infusion of 5-FU and calcium folinate. Onkologie 2003;26:469-472.

5 Trissel LA, Martinez JF, Xu QA: Incompatibility of fluorouracil with leucovorin calcium or levoleucovorin calcium. Am J Health Syst Pharm 1995;52: 710-715.
6 Arzneimittelkommission der Deutschen Apotheker: Portverschlüsse bei gleichzeitiger Gabe von 5FU und Leucovorin in einer Pumpe. Dt ApothZ 2002;142:16/6116.

7 Hartung G, Hofheinz RD, Wein A, Riedel C, Rost A, Fritze D, Kreuser ED, Drees M, Kühnel J, Hehlmann R, Queisser W: Phase II study of a weekly 24-hour infusion with 5-fluorouracil and simultaneous sodium folinic acid in the first-line treatment of metastatic colorectal cancer. Onkologie 2001;24 457-462. 